\title{
VOCES DESDE LA MARGINALIDAD ACUÁTICA: CAMINOS FLUVIALES HACIA UNA ARQUITECTURA DEL PLURIVERSO*
}

\author{
UlRICH OSLENDER ${ }^{* *}$ \\ Doctor Geógrafo. Profesor de la Florida International University, Miami \\ https://dx.doi.org/10.12795/astragalo.2018.i25.06
}

\section{PALABRAS CLAVES}

- modernidad; colonialidad del poder; conflicto ontológico; epistemologías acuáticas; Pacífico colombiano; comunidades negras; espacio acuático; epistemologías del Sur

\section{INTRODUCCIÓN}

En 1991, Colombia aprobó una nueva Constitución que iba a transformar significativamente las relaciones entre la nación y su población afrodescendiente. Entre otras cosas, proporcionó una legislación que otorgaría títulos colectivos de tierras a las comunidades negras rurales que viven a lo largo de la gran cantidad de cuencas hidrográficas en la región de la costa del Pacífico. Si bien se ha escrito mucho sobre la ley aprobada posteriormente, conocida como Ley 70 de 1993, en este artículo quiero examinar el mundo del que habla esta legislación. En particular, quiero mostrar cómo lo que yo llamo "epistemologías acuáticas locales" -las formas culturalmente específicas y basadas en el lugar de conocer un ambiente profundamente

\footnotetext{
* Este artículo se basa en una versión anterior en inglés (Oslender 2018).

** Ulrich Oslender es un geógrafo político y cultural con intereses regionales en América Latina. Obtuvo su Ph.D. en Geografía en la Universidad de Glasgow, y actualmente es Profesor Asociado de Geografía en el Departamento de Estudios Globales y Socioculturales de la Florida International University en Miami. Ha publicado más de cincuenta artículos y capítulos de libros tanto en inglés como en español, principalmente en relación con la teoría de los movimientos sociales y la geografía política. Es autor de dos libros, el más reciente "Las geografías de los movimientos sociales: la movilización afrocolombiana y el espacio acuático" (Duke University Press, 2016) y coeditado "Bridging Scholarship and Activism: Reflections from the Frontlines of Collaborative Research” (Michigan State University Press, 2015). uoslende@fiu.edu
} 
acuático- están en el centro de una cosmovisión rural afrocolombiana que constituye una ontología relacional que desafía los marcos de la modernidad euroamericanista y su pensamiento del desarrollo. Por lo tanto, el hecho de excavar estas epistemologías acuáticas puede considerarse como una contribución para pensar e imaginar una arquitectura del pluriverso, o un mundo de muchos mundos. Examinaré esta ontología relacional a través de viñetas etnográficas, que son el resultado del trabajo de campo que realicé en la región de la costa del Pacífico colombiano a fines de los 90 y principios de los 2000.

La noción del pluriverso es un eje central en el pensamiento descolonial que comenzó a tomar forma en América Latina en los años noventa. Desde esta corriente se ha deconstruido varias facetas de la cosmología occidental y su perspectiva universalista sobre el mundo que se expresó, primero, en la explotación colonial y, luego, en la dominación neocolonial a través de lo que Walter Mignolo (2011) llama "matriz colonial del poder". Aníbal Quijano (2000, 2007), uno de los primeros exponentes de esta corriente crítica, acuñó la frase "la colonialidad del poder", un concepto que busca interrogar el legado del colonialismo europeo en los órdenes y formas sociales contemporáneas de conocimiento. En particular examina las formas de discriminación racial que emana de la clasificación colonial y la dominación en términos de raza.

Sobre la base del trabajo pionero de Quijano, otros autores han ampliado estas ideas a las críticas descoloniales de la teoría de la modernización y la globalidad imperial (Mignolo y Escobar 2010, Slater 2004); de cosmología y hermenéutica occidentales
(Mignolo 2011) y “epistemicida” (Santos 2014); entre otros. ${ }^{1}$

La idea básica sobre el pluriverso es (y quizás debería ser) simple: hay mundos distintos que históricamente han sido marginados y reprimidos por una cosmología occidental y su tendencia universalizadora que reclamaba una posición superior para sí misma con respecto a esos "otros" mundos. El libro Orientalismo de Edward Said (1978) se puede considerar como un gran sitio de excavación del diferencial de poder que permitió que la epistemología y la hermenéutica occidentales promulgaran su superioridad sobre una multiplicidad de mundos "otros" que se categorizaron como "El Oriente" y se abrieron a la explotación imperial occidental. La noción de pluriversalidad en contraste nace de un deseo descolonial de romper esos lazos de dominación y constituye un llamado a la coexistencia de muchos mundos como un reconocimiento del enredo de diversas cosmologías, de las cuales el universalismo occidental es solo una.

Ahora, si bien estas contribuciones teóricas han sin duda avanzado nuestra comprensión de la matriz colonial del poder, me parece que gran parte del debate sobre la pluriversalidad carece de evidencia etnográfica concreta para respaldar afirmaciones conceptuales que con frecuencia están envueltas en un lenguaje innecesariamente complicado. Creo que la crítica teórica del impulso de la modernidad occidental para negar, silenciar y deslegitimar

1 La revista colombiana Tabula Rasa se ha convertido en un importante vehículo de publicación de ideas sobre la descolonialidad proveniente de académicos latinoamericanos (ver http://www.revistatabularasa.org/). 
a otras culturas, pueblos y cosmologías debería ir acompañada de trabajos etnográficos que saquen esos mundos "otros" de su invisibilidad con el fin de facilitar un compromiso descolonial más profundo y arraigado con las experiencias vividas en un mundo pluriverso. Es lo último que pretendo poner en primer plano en este artículo, en lo cual propongo un encuentro con un "territorio de diferencia" particular (como lo llama Escobar, 2008): la región de la costa del Pacífico colombiano. Invitaría al lector ahora a "morar en la frontera", como diría Mignolo tal vez (movilizando el pensamiento de Gloria Anzaldúa), y a sumergirse en la ontología relacional del "espacio acuático" para imaginar, sentir, soñar y oler cómo podría ser un mundo pluriverso.

\section{EL "ESPACIO ACUÁTICO” EN LAS TIERRAS BAJAS DEL PACÍFICO COLOMBIANO $^{2}$}

Con una línea costera de alrededor de 1,300 kilómetros, que se extiende desde Ecuador en el sur hasta Panamá en el norte, las tierras bajas del Pacífico cubren un área de casi diez millones de hectáreas de selva tropical. Separadas del interior de Colombia por la cordillera de los Andes occidentales, las tierras bajas se han descrito de diversas maneras, como el "litoral recóndito" (Yacup 1934) o la "periferia de la periferia" (Granda 1977) debido a su marginalidad física y económica en relación con el resto del país. Inicialmente de interés para los colonizadores españoles por sus ricos yacimientos de oro aluvial, la economía de la región se ha caracte-

2 La narrativa etnográfica en el resto de este artículo está adaptada de mi monografíaThe Geographies of Social Movements, publicada por Duke University Press (Oslender 2016). rizado por ciclos de "auge y caída", como la explotación de tagua y caucho en la primera mitad del siglo XX, la extracción de madera desde la década de 1960 y, más recientemente, agroindustrias como plantaciones de palma aceitera y cría de camarones. A lo largo de estos paradigmas económicos cambiantes, una población local resistente, compuesta mayoritariamente por personas de ascendencia africana, ha continuado practicando una economía de subsistencia diversificada en las áreas rurales basada en la pesca, la caza, la agricultura, y la recolección

La región del Pacifico colombiano (mapa producido por el autor)

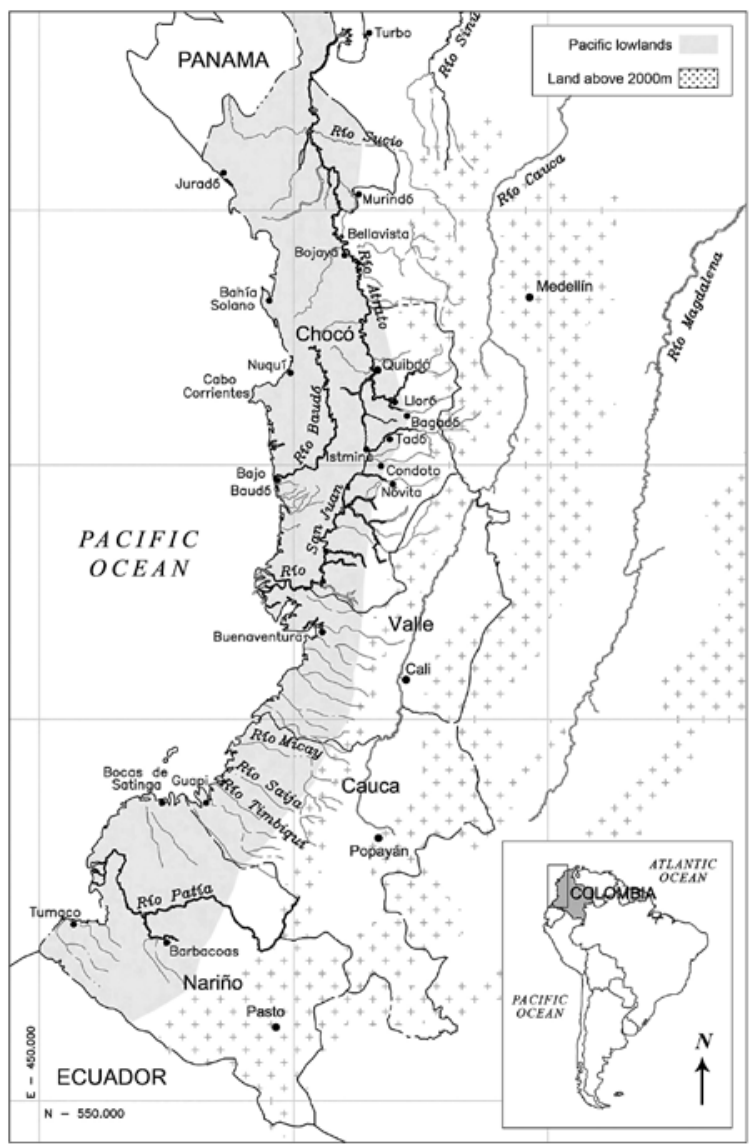


de oro artesanal a pequeña escala para sus necesidades cotidianas.

Eso fue todo lo que sabía sobre esta región en febrero de 1995, cuando bajé de la avioneta Satena en el aeropuerto de Tumaco, la ciudad más al sur y la tercera más grande de la costa del Pacífico. En Bogotá había conocido a Robin Hissong, quien trabajó en Proyecto Biopacífico, un proyecto de conservación de la biodiversidad financiado por el Banco Mundial. Como geógrafo tenía un interés en la conservación, la biodiversidad y el desarrollo sostenible. Las tierras bajas del Pacífico colombiano parecían un lugar interesante donde estas nociones se superponían de manera compleja con una política de identidad emergente de la población afrodescendiente de la región. Por lo tanto, no dudé cuando Robin extendió una invitación para acompañarla a Guapi, una pequeña ciudad costera a unos 150 kilómetros al norte de Tumaco, donde necesitaba entregar un equipo a la oficina regional de Proyecto Biopacífico.

Este fue mi primer viaje en lancha rápida recorriendo el laberinto de manglares que conforman la costa sur de las tierras bajas del Pacífico. Nuestro capitán sugirió que deberíamos viajar "por dentro", avanzando lentamente por los numerosos canales serpenteantes que atraviesan el paisaje de manglares. Advirtió contra la navegación "por fuera”, en mar abierto, ya que el Océano Pacífico era duro ese día. Bien, pensé, de esa manera podría ver el área aún mejor.

Era mediodía cuando nos pusimos en marcha. El cielo estaba cubierto de nubes oscuras, cuando salíamos de la Bahía de Tumaco. La humedad estaba cerca del noventa por ciento. Hacía calor y no entendía por qué habíamos esperado tanto. Sería un largo viaje, ocho horas o más. Robin incluso había mencionado que tendríamos que pasar una noche en el camino.

“A quién estamos esperando?”, le pregunté al capitán, quien había dicho algo sobre esperar a Marea.

$$
\text { “Cuándo llega Marea?” ... }
$$

Risas por todas partes. Esa fue una de estas preguntas gringas tontas. Al parecer no había suficiente agua en los canales del manglar. Así que tuvimos que ser pacientes y esperar a que llegara la marea alta. Más tarde, me daría cuenta de cómo los cambios diarios de las mareas impactaban en los patrones de la vida diaria de mil y una maneras. Los horarios de viaje se establecen de acuerdo con las mareas, calculando no solo la disponibilidad de agua en los manglares costeros sino también en las partes altas de los ríos. Las llanuras aluviales tienen un gradiente tan bajo que el impacto de la marea se siente hasta veinte kilómetros río arriba. La marea alta también empuja el agua salada río arriba, un mal momento para lavar la ropa o ir a buscar agua potable del río, por ejemplo.

Sentado en el embarcadero en Guapi el día después de dejar Tumaco, observé la majestuosa tranquilidad con que el río Guapi descendía a su encuentro con el Océano Pacífico. Unas canoas en el río, impulsadas por la fuerza del remo de un solo ocupante, se dirigían hacia el embarcadero desde aguas abajo, mientras la marea creciente les prestaba una mano. Volverían más tarde ese día a sus aldeas río abajo, cuando la marea baja iba a facilitar un viaje más rápido. 
Fue allí, en el embarcadero de Guapi, donde pasé innumerables horas en los años siguientes, donde la noción del "espacio acuático" comenzó a tomar forma. Los antropólogos y geógrafos han descrito las interacciones de las poblaciones rurales con la selva tropical en términos de adaptación humana a un ambiente natural difícil (Arocha 1999, Friedemann 1974, West 1957, Whitten 1986). Sin embargo, sentado en el embarcadero de Guapi - observando a las canoas que llegaban, las mujeres que lavaban la ropa en la orilla del río, los niños que jugaban en el agua, los viajeros que esperaban embarcarse - sentí que eran más que simples respuestas de adaptación. El discurso de la adaptación mantiene una separación rígida entre cultura y naturaleza, la cual parecía disolverse en la práctica ante mis ojos. La idea del "espacio acuático" que estaba echando raíces en ese entonces en mi imaginación se debe más a una comprensión espacial deleuziana de estas complejas y cambiantes relaciones entre seres humanos y no humanos en términos de ensamblajes (Deleuze

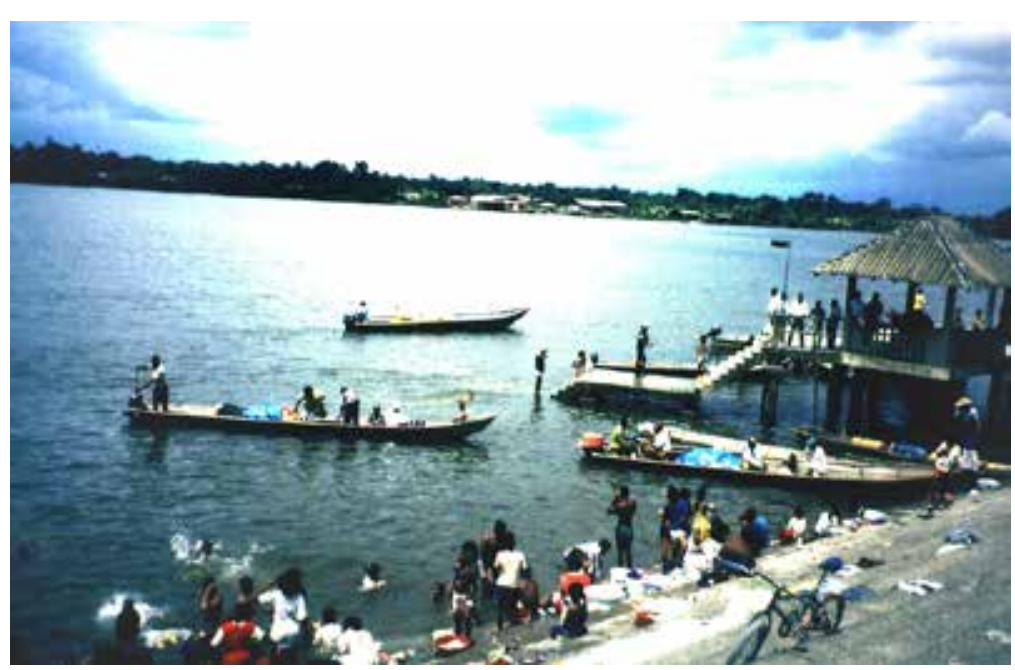

Embarcadero de Guapi, 1999 (foto del autor) y Guattari 2007). Quiere romper con la noción de exterioridad de una naturaleza ya existente a la que la cultura simplemente se adapta. En particular, me refiero con "espacio acuático" al conjunto singular de relaciones espaciales que resulta de los enredos entre seres humanos y un entorno acuático caracterizado por redes de ríos, rangos de marea significativos, manglares laberínticos e inundaciones frecuentes (Oslender 2004, 2016).

En 1999 pasaba muchas horas de la tarde en el patio semicubierto de la casa que alquilé en la Calle Segunda en Guapi, sentada con Doña Celia Lucumí Caicedo, una curandera y partera tradicional, con quien compartí esa casa. A medida que las lluvias azotaban los tejados, generando un ruido atronador que ahogaba toda posibilidad de conversación, simplemente miramos hacia adelante observando cómo el agua de lluvia golpeaba las plantas tropicales del patio y llenaba rápidamente los cuatro barriles -uno en cada esquina-fuente única de suministro de agua a domicilio. Estos eran momentos de gran paz y tranquilidad en los que parecía que todos nos convertimos en agua. Doña Celia se perdía en sus pensamientos entonces. Caminando a lo largo de las orillas de su río en su imaginación, como me contaría más tarde, le trajo a la vida recuerdos de su infancia creciendo 


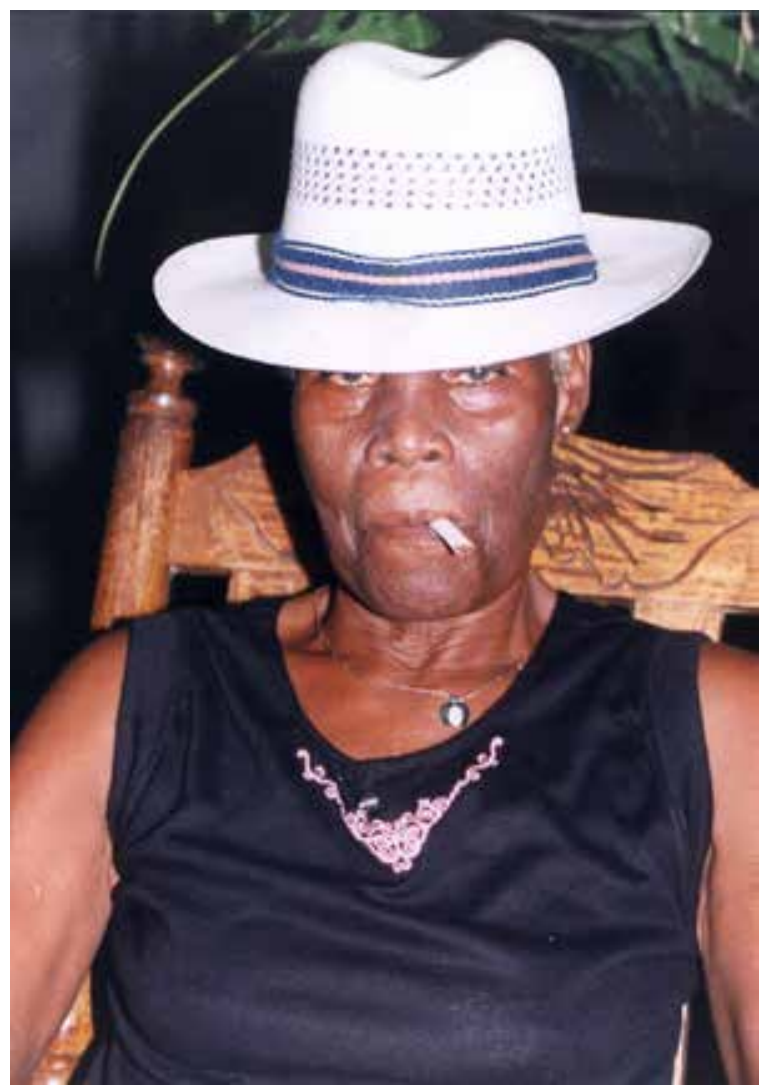

Doña Celia Lucumí Caicedo, fumando "pa'dentro" en el patio de nuestra casa en la Calle Segunda, Guapi, 1999 (foto del autor)

a lo largo de las cabeceras del río Guapi. "A mi río, no lo olvido", murmuraba. Ella era una con su río entonces.

En ese patio en Guapi, con las lluvias golpeando el techo, comencé a preguntarme cómo las particularidades de este lugar -su alta humedad durante todo el año, sus culturas a base de agua, sus vías fluviales, su gente-queescucha-las-mareas- figuraban en la creación del movimiento social de comunidades negras que había comenzado a movilizarse desde prin- cipios de la década de 1990 en torno a un discurso constitucional recién formado sobre la negritud y los derechos culturales y territoriales de los afrocolombianos. He examinado estas preguntas en detalle en otra parte (Oslender 2016). Aquí quiero explorar las particularidades del lugar que encontré en Guapi a través de la noción de "epistemologías acuáticas locales", las formas basadas en el lugar y culturalmente específicas de conocer un ambiente profundamente acuático, tal como me las reveló una de los sabios de la región.

\section{EPISTEMOLOGÍAS ACUÁTICAS LOCALES: DOÑA CELIA LUCUMÍ CAICEDO - IN MEMORIAM ${ }^{3}$}

\begin{abstract}
Nací en Balsitas, Guapi arriba, tres calles abajo del pueblo de Balsitas, en un punto que se llama La Corriente. Estabayo muchachacuandomimamá me mandaba a Balsitas a hacer mandados. Sin saber bañar. No sabía bañar, no. Cuando llegaba la corriente, cogía mi potrillo, y chi, chi, chi, a pie, así lo subía al cabezón de la corriente. Así me embarcaba, y chim, chim, chim, así me subía todas las tres corrientes. Porque tres no más eran. La de allí que uno cogía de la casa era allí calle, calle, calle, hasta que llegaba a otra calle. Y que tenía después un regaderito, pero no corriente maternal.
\end{abstract}

3 Las citas en cursiva en esta sección provienen de más de cincuenta horas de entrevistas transcritas con Doña Celia Lucumí Caicedo que grabé en Guapi entre marzo y julio de 1999. Doña Celia falleció el 21 de diciembre de 2013. Q.e.p.d. 
De allí me iba subiendo por este lado derecho, yacuando yallegababastante arriba, pum, y me acostaba al lado de los pies. Diablita desde chiquita, pero que no sabía bañar. Pero que mi mamá no tenía ese temor que yo no sabía bañar. Que de pronto podía meter la palanca mal metida y podía darcarambolasalagua. Asíhastaque llegaba a Balsitas.

La noción de calle requiere una explicación aquí. En las zonas rurales de las tierras bajas del Pacífico hay muy pocas calles. El ambiente húmedo, a menudo inundado con su gran cantidad de ríos y arroyos más pequeños es altamente inadecuado para la construcción de carreteras. Cuando los afrocolombianos hablan de "calles" en este entorno, aplican parámetros descriptivos urbanos a un paisaje rural. Lo que miden con la denominación "calle" es, de hecho, la distancia entre dos meandros del río. Cuando Doña Celia habla de viajar tres calles río arriba, esto significa navegar por tres curvas del río antes de llegar a su destino. La noción de "calle" es, por lo tanto, una medida flexible, ya que la distancia métrica entre las curvas del río cambia. Se supone que uno conoce la sección del río en cuestión y, por lo tanto, forma parte central de las epistemologías acuáticas locales en las tierras bajas del Pacífico.

Llegaba a Balsitas andel finado Joaquín Ledesma, el papá de Andelmo Ledesma. Que era muy de amigo con mi papáy mi mamá. Cogía mi mamá,y en un pañuelo amarraba alguna cosa. Ahora sí, le mandaba el papelito al fi- nado Joaquín. Ahora sí, cogí el papelito del finado Joaquín, ponía allí tal cosa, y tal cosa. Y ahora sí, lo echaba en mi talega y me decía: "Tenga, mija, llévale a Misia Lucha. Y dígale a Misia Lucha que no la mande, que Usted no sabe bañar. Siéntese, oyó, mija!" Allí como'ita y bien manda' ita llegaba yo, ponía mis cosas en la proa del potro, y ahora sí, cogía mi canaletico y prum, me sentaba al plan del potro. Y ahora sí, póngalo cuidado, hasta que llegaba a la casa, más rápido que hacía los mandados. Cuando mi mamá creía que yo iba llegando a Balsitas, era cuando iballegando allía la casa. Ahora sí, llegaba y le entregaba. Llegaba y le decía: "Mamá, a Don Joaquín, que el día que suba pa' Balsitas, que se vean, oyó." Porque yo le avisaba la razón que él le mandaba. "A Don Joaco, que el día que suba pa' Balsitas que se vean'.

Se dice que los niños en las áreas rurales de la costa del Pacífico se mueven en pequeñas canoas antes de que realmente aprendan a caminar sobre sus pies. El río no es solo el lugar donde juegan. También es la carretera principal que los conecta con vecinos, amigos y familiares que viven a lo largo del mismo río. Desde una edad temprana, los niños se incorporan a la vida adulta. Las niñas ayudan a sus madres en el hogar, lavan la ropa, limpian los platos y cuidan a sus hermanos y hermanas más pequeños, mientras que los niños van a pescar para complementar las comidas de la familia. Doña Celia, al igual que muchas otras niñas, también trabajó junto a su madre y su 
abuela en las minas de oro, lavaba la arena en su batea, cuando tenía solo ocho años. ${ }^{4}$ Como Doña Celia nos dice aquí, su madre la usó como una especie de "mensajero fluvial" para enviar información o bienes a amigos, vecinos y familiares. El río en este contexto funciona como el camino principal que la pequeña Celia tuvo que navegar, una acción en la que adquirió una habilidad considerable. Celia, la mensajera fluvial en su camino acuático hacia los tramos superiores del río Guapi, recuerda:

Entonces, sucedía que mi mamá me mandaba adonde mi abuelo Juan Gregorio. A traerle estas cosas que encontraba ella. Llegaba yo, cogía esas cosas, cogía mi potrillito, y me iba. Llegaba allá, le daba en nombre de Dios a mi abuelo, ahora sí, llegaba, me echaba su bendición, y yo le decía, "Abuelo, aquí le manda mi mamita." Él era pescador de mojarra. Muchas veces cuando era hora de almuerzo que yo le llevaba su comida, le topaba sentado allí en una playa. Allí cogía mojarra, cogía sábalo, cogía una sabaleta redonda que es así. Yya había cogido, sea posible, dos machos, dos sábalos, y dos sabaletas. Ahora sí me decía, "Súbalo pa' encima de la casa mía". Y subía yo con ese almuerzo que le llevaba, ahora sí, bajaba con un envase, pa'subíel pescaoél había cogido.

4 Una batea es un cuenco redondo, poco profundo, tallado en madera, que se utiliza en la extracción tradicional de oro en la costa del Pacífico colombiano, una actividad que suelen realizar las mujeres y las niñas pequeñas, las bateadoras. Para más información sobre la minería artesanal, vea el trabajo fascinante de West (1952).
Mi abuelo Juan Gregorio, el papá de mi papá. Él era que pescaba. [...] Eso era costumbre pues. Tanto élla quería a mi mamá, y ella lo llegó a querer a él, entonces mi mamá hacía la comida en la casa, y con nosotros se la mandaba ahí a la casa de él. Vivíamos de calle, por ejenplo [sic], nosotros vivíamos aquí en esta calle. Y en la calle arriba vivía mi abuelo. En la vuelta. Tocaba ir en potrillo. No había camino. Por este lado donde vivíamos nosotros todo era loma. Por allá por el otro lado, pues, era rastrojo. Y le digo, que ya cogía mi abuelo, "Vea mija, coja el pescado, ahí en el canasto y llévese allá a su mamá". Ese pescado iba pa' donde mi mamá. Llegaba, no más que arreglaba ese pescao. Si era de mediodía, ahora sí hacían merienda, y le mandaba otra vez a mi abuelo. Así es que yo era una sardinita cuando quedaba ella arreglando ese pescado allí, e iba yo donde mi abuela, iba llevando a mi abuela Juana María. Bueno, mi abuela ya me esperaba más dispersa, vivía arriba bastante, donde los otros

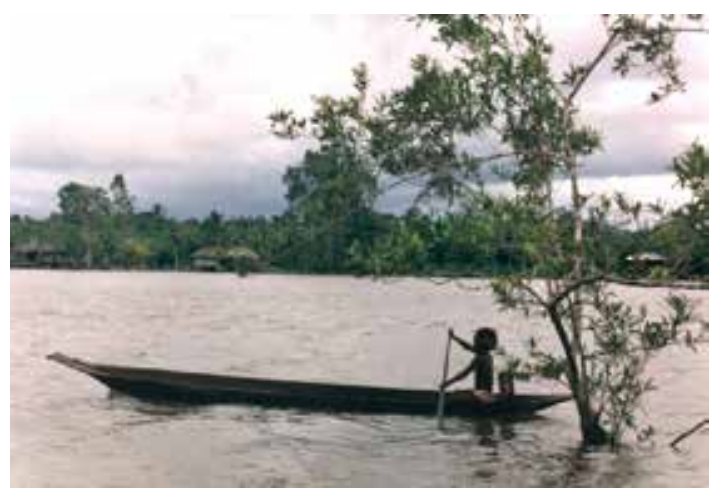

“Mensajera fluvial”, Río Guapi, 1999 (foto del autor) 
hijos. Ella bajaba ande mi mamá por turno. Porque yo a mis abuelos toditos los conocí divorciados de las mujeres.

En la narración de Doña Celia, el río no es solo el sitio que proporciona alojamiento, refugio y espacio vital, sino también el desempeño de la familia. Las relaciones con los miembros de la familia se articulan en los movimientos diarios alrededor del paisaje del río. Como tal, el río es también una fuente de apego emocional y de un sentido particular de pertenencia; lo que yo llamo un "sentido de lugar acuático". El geógrafo cultural estadounidense Robert West comentó ya en la década de 1950 sobre esta relación cercana e íntima entre el individuo y el río. Como observó, el río era un punto central de referencia en la formación de identidad y en las prácticas discursivas cotidianas: "Las personas que viven en un río determinado se consideran a sí mismas como una sola comunidad. [...] Los negros [sic] hablan de 'nuestro río', o mencionan, por ejemplo, que 'somos del Río Guapi' o 'somos Guapiseños' [sic], indicando su apego social a un río dado" (West 1957:88).

Hoy en día, el río sigue siendo la referencia geográfica más inmediata para los habitantes de la costa colombiana del Pacífico. En lugar de referirse a un asentamiento o aldea, cuando se les pregunta sobre su lugar de origen, los afrocolombianos nombran el particular río a cuyas orillas viven. Como el poeta guapireño Alfredo Vanín me contó: “Si alguien pregunta: ‘¿De dónde eres?’, Entonces la respuesta sería 'Yo soy del río Chagüí', aquí en Nariño. O 'Soy del río Saija', en el departamento del Cauca. En lugar de hablar de la aldea, primero está el río”.
De hecho, los ríos se consideran los lugares de donde emergen los individuos y se sumergen de nuevo cuando llega el momento del viaje final, regresando en cuerpo si es posible, pero siempre en espíritu, al río de origen en el momento en que se acerca la muerte. Tal fue el viaje imaginativo de Doña Celia, cuando hace algunos años sufrió de fiebre alta y sintió que había llegado el momento de que su cuerpo dejara esta vida. Reflejando "la naturaleza dialógica de la relación de las personas con el lugar" (Buttimer 1976:284), regresó a su río en su imaginación, a su origen, ya que su vida estaba completando el círculo:

Allí me fui a todos los puntos de mi
río donde yo me crié. Los estuve ca-
minando en ese instante que me morí.

\section{LA LÓGICA DEL RÍO}

El río es fundamental para todas las actividades económicas, domésticas y sociales en las tierras bajas del Pacífico. Las casas se construyen sobre pilotes a lo largo de las orillas del río, el transporte se realiza a través del río, la pesca y la recolección de mariscos son importantes contribuyentes a la dieta local. El río es también el espacio de interacción social per se, donde la gente se baña, las mujeres lavan la ropa, y los niños vienen a jugar. En estas constelaciones socio-espaciales, el río emerge como un espacio colectivo de interacciones sociales cotidianas basadas en la cooperación y la solidaridad. Como Silveria Rodríguez, líder de la comunidad en Guapi, me dijo en abril de 1996: "Me acuerdo, como niña nunca fui sola 
a lavar la ropa en el río; siempre fuimos por lo menos cuatro. O a lavar ollas. Siempre hicimos las cosas juntas".

En la imaginación geográfica local, las varias secciones del río están intrínsecamente conectadas, y el río se refiere no solo al río principal sino también a los afluentes y las tierras circundantes. Las comunidades de la sección media o en las cabeceras, por ejemplo, dependen de las actividades productivas de las comunidades que viven cerca del delta del río, especialmente la provisión de peces y moluscos. Durante una de mis primeras entrevistas en la región del Pacífico en abril de 1996, el historiador y poeta afrocolombiano Alfredo Vanín explicó:

\footnotetext{
"La parentela se iba extendiendo por un río, de tal manera que había un pedazo de tierra, respaldo de monte, perteneciendo a un miembro de una familia que se iban dispersando a lo largo de los ríos. Y la tierra en general pertenecía a la familia y podía dividirse entre los hijos también. Pero estaba en nombre de la cabeza de la familia. O sea, que sí había una individualidad en la tierra así no estuviera titulada."
}

Por lo tanto, la interconexión a lo largo de una cuenca fluvial no solo es evidente en términos de intercambio de alimentos, sino también en términos de distribución de la tierra y relaciones de propiedad. Activistas del Proceso de Comunidades Negras PCN (una de las agrupaciones principales del movimiento social de comunidades negras en Colombia) se han referido a estas relaciones sociales espacializadas a lo largo de las cuencas de los ríos en términos de "la lógica del río" (véase también Oslender 2002):

"En la lógica del río las propiedades del uso del territorio están determinadas por la ubicación: en la parte alta del río se da énfasis a la producción minera artesanal, se desarrollan actividades de cacería y recolección en el monte de montaña, hacia la parte media el énfasis se da en la producción agrícola y el tumbe selectivo de árboles maderables, también se desarrollan las actividades de cacería y recolección en el monte de respaldo; hacia la parte baja el énfasis se da en la pesca y recolección de conchas, moluscos y cangrejos compartidas con la actividad agrícola. Entre todas las partes existe una relación continua del arriba con el abajo y viceversa y del medio con ambas, caracterizado por una movilidad que sigue el curso natural del río y la naturaleza, cuyas dinámicas fortalecen y posibilitan las relaciones de parentesco e intercambio de productos siendo en esta dinámica la unidad productiva la familia dispersa a lo largo del río" (PCN 1999:1).

Este río es muy diferente del que se describe en la obra maestra literaria de Gabriel García 
Márquez Cien Años de Soledad (1967). Allí, José Arcadio Buendía está desesperado por el atraso de su pueblo y cautivado por los últimos y magníficos instrumentos científicos que Melquíades y su compañía de gitanos viajantes traen periódicamente a la gente de Macondo. Desde los dientes falsos hasta las alfombras voladoras y los secretos de la alquimia, todos estos maravillosos avances provienen de algún lugar más allá del río, un río que separa a Arcadio Buendía y su gente de la modernidad. Un día confiesa a su esposa Úrsula en su desesperación: "En el mundo están sucediendo cosas increíbles ... Al otro lado del río hay todo tipo de instrumentos mágicos mientras nosotros seguimos viviendo como burros" (García Márquez 2006: 8). Este río separa el mundo local y atrasado de otro mundo científicamente avanzado. El río es una frontera, un obstáculo, un impedimento; retiene a las personas y su imaginación.

No es así en las tierras bajas del Pacífico. Allí, el río conecta y muestra una orientación espacial distinta. El río no se ve como un obstáculo a cruzar, sino como una línea de conexión a seguir. Uno no mira más allá del río, sino río arriba y abajo. Toda la orientación espacial y ontológica hacia el río es completamente distinta de la retratada en la novela de Gabo.

El paisaje en las tierras bajas del Pacífico colombiano también tiene su propia temporalidad. Tal vez más que cualquier otro fenómeno, es el ritmo de marea que ha dado lugar a patrones de tiempo que se resisten a ser moldeados en un reloj de la modernidad 24/7. En cambio, las mareas proporcionan un ritmo temporal que se orienta a los ciclos lunares. Vas contra este ritmo a tu propio riesgo. Como relató Ro- bert West en sus navegaciones por la costa sur del Pacífico en la década de 1950: "Los viajes por adentro a lo largo de los canales del interior deben ser calculados para que correspondan con los períodos de marea alta. Más de una vez, el escritor ha estado varado durante varias horas en una canoa atrapada en el fondo fangoso de un estero durante la marea baja, siendo molestado por moscas negras y mosquitos hasta que el agua subió lentamente con la marea entrante" (West 1957: 70; cursivas en el original).

\section{CONVIVENCIA ACUÁTICA: APROVECHANDO LA MAREA}

El pueblo de Guapi se encuentra a unos diecisiete kilómetros de la desembocadura del río Guapi, a una altura de dos metros sobre el nivel del mar. Un rango de marea de 4.5 metros y un bajo gradiente del río significa que dos veces al día en marea alta el agua salada sube mucho más allá de Guapi. Durante períodos relativamente secos, los niveles de intrusión de agua salada pueden ser significativos. Esto también significa que las actividades como lavar la ropa en el río se realizan durante la marea baja para evitar el contacto de la ropa con agua salada. La gente local es muy consciente de este ritmo temporal y planifica las actividades del día de acuerdo con el reloj de mareas en lugar de un reloj de pulsera insensible a las mareas.

Además, durante la marea baja, las aguas que retroceden exponen los manglares costeros, una zona importante de productividad ecológica y actividad económica. Las recolectoras de mariscos conocidas como concheras, por ejemplo, viajan a áreas de manglares, a menudo desde lejos, para recolectar mariscos 
que viven enterrados en el lodo. Para extraerlos más fácilmente, lo hacen durante la marea baja, cuando los esteros están expuestos. Las concheras planean meticulosamente sus viajes a las áreas de manglares, calculando su salida en un momento tal durante la marea baja que las aguas del río Guapi retroceden acelerando su viaje y que, al llegar, las planicies están expuestas. Pueden pasar hasta cinco horas recolectando mariscos, después de lo cual esperan que las crecientes aguas de la marea alta les ayuden a navegar aguas arriba en sus canoas, conocidas como potrillos. Este sistema de transporte hace posible que las concheras viajen grandes distancias hacia y desde los manglares con relativa facilidad. Es solo una de las muchas actividades que coproducen el espacio acuático como un ensamblaje de relaciones socio-espaciales complejas entre seres humanos y no-humanos.

Y no son solo las concheras las que establecen sus horarios de viaje de acuerdo con el ritmo de las mareas. Los leñadores también son personas que escuchan a las mareas, cuyos días laborales muestran cambios en las temporalidades. El antropólogo colombiano Eduardo Restrepo ha pasado mucho tiempo entre los cortadores de árboles en el guandal, un pantano de palmeras de tierras inundadas en gran parte que se encuentran principalmente en la parte sur del departamento de Nariño. Analizando sus patrones de trabajo, observa que el efecto de las mareas "determinará no sólo la hora adecuada para ir a trabajar, sino también la de la salida, con lo cual se acortan o alargan, según el caso, las jornadas de trabajo. Este factor, entre otros, hace que la jornada de trabajo en el Pacífico posea tiempos efectivos diferenciales" (Restrepo 1996b:366).
De hecho, las actividades de tala dependen de muchas más formas del ritmo de las mareas, particularmente cuando la madera tiene que ser transportada a distancias más grandes desde el sitio de tala al aserradero. Una vez derribado, un árbol es arrastrado por el suelo del bosque a un canal de agua o río cercano. Según Restrepo (1996a: 252-253), existen dos formas distintas y complementarias de transportar los troncos. Una forma es sobre tierra e implica la construcción temporal de carreteras mediante la colocación de troncos delgados separados por unos tres metros y paralelos entre sí desde el sitio de tala a un curso de agua. El árbol derribado (tuco) luego se tira sobre estos troncos, hasta que llega a la vía fluvial en la que se puede transportar río abajo. Una "carretera" de mayor duración para el transporte de troncos a menudo se construye en forma de zanjas de un metro de ancho y dos metros de profundidad. Estas cunetas se llenan con agua después de períodos prolongados de precipitación o durante la marea alta. Cuando se llenan con suficiente agua, los troncos se colocan en ellos y flotan hacia un canal más grande y más ancho. Allí, dependiendo del ancho del canal, varios troncos se unen con fibras naturales para formar una balsa, que luego flota hacia abajo hasta que llega al aserradero. Se puede argumentar que tanto las cunetas como las carreteras constituyen la infraestructura fundamental para la extracción de madera en la costa sur del Pacífico, una infraestructura que se aprovecha del espacio acuático como ensamblaje de relaciones socioespaciales en las que los seres humanos y nohumanos interactúan en maneras complejas. 


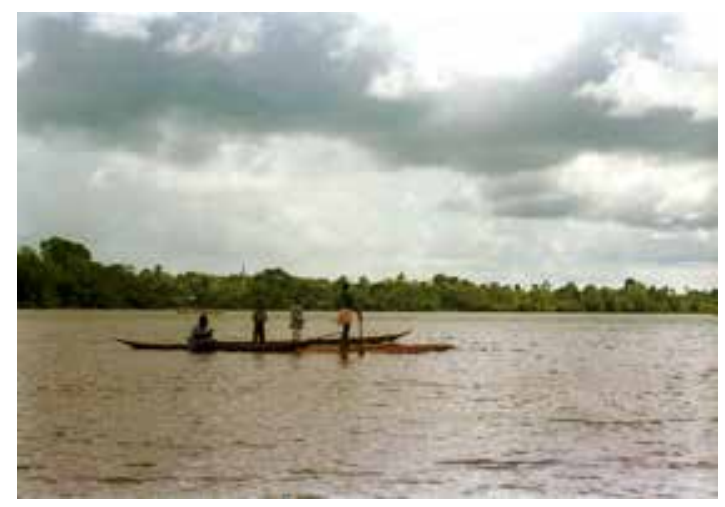

Balsa hecha de árboles cortados por leñadores, Río Guapi, 1999 (foto del autor)

\section{EN LUGAR DE CONCLUSIONES... APERTURAS: PENSAR EL PLURIVERSO}

He presentado en este artículo un acercamiento a las tierras bajas del Pacífico de Colombia no a través de textos legislativos o movilización política, sino a través de una etnografía profunda que revela un mundo de vida afrocolombiano rural enredado en relaciones complejas con el entorno acuático de la región. El espacio acuático como un ensamblaje de relaciones socioespaciales complejas, sostengo, es una clave central de la ontología relacional en la región del Pacífico que sectores del movimiento social de las comunidades negras, en particular el Proceso de Comunidades Negras PCN, han movilizado en sus demandas por derechos culturales y territoriales.

Se puede argumentar, por supuesto, que el espacio acuático en estos días se está transformando, con la gente local a menudo profundamente enredada como agentes en tecnologías y procesos de la modernidad. Algunos trabajan en plantaciones de palma aceitera, otros usan mercurio o dragas mecánicas en la minería de oro, muchos están ahora involucrados en el cultivo ilegal de coca, muchos viajes por el río hoy en día son en lancha motora. Todas estas cosas pasan. Las poblaciones negras rurales son modernas también. Sin embargo, al mismo tiempo, las prácticas de producción tradicionales y las economías de subsistencia locales siguen siendo fundamentales para los mundos de vida rural resilientes que forman la columna vertebral de las visiones de proyectos de vida alternativa promovidos por PCN basados en la diferencia. La suya es una visión de pluriversidad que parte de la ontología relacional acuática de las tierras bajas del Pacífico. Estos activistas defienden un mundo basado en "modelos locales de la naturaleza” (Escobar 2008), o lo que Restrepo (2013) llama desde una "gramática local del entorno". La politización de esta visión puede considerarse como una ontología política, un desafío al universalismo occidental implícito en el proyecto de la modernidad. Desde este punto de vista, los conflictos ontológicos apuntan a una multiplicidad de formas de estar en el mundo. En otras palabras, son testigos de un verdadero pluriverso existente.

Podemos pensar el pluriverso tal vez como un "tercer espacio", en el cual, según Homi Bhabha (1994: 39), se puedan adoptar nuevas identidades poscoloniales, una posición desde la cual puede ser posible "eludir la política de la polaridad”. Para Ed Soja (1996), el tercer espacio contiene formas binarias de pensar sobre el espacio, pero también las supera en la medida en que ocurren nuevas cosas, lo que permite una práctica potencialmente emancipatoria. Esto es claramente lo que sugieren los 
debates descoloniales sobre el pluriverso. $\mathrm{Y}$ mientras estas ideas están impregnadas de una buena dosis de pensamiento utópico, podemos preguntarnos: ¿no está en la utopía, en el tercer espacio, y en el pluriverso, que trascendemos las oposiciones binarias en un esfuerzo por imaginar un mundo de diferencias que conviven entre ellas en lugar de siempre entrar en conflicto? Este parece ser el mensaje, cuando Santos (2006) examina el Foro Social

\section{REFERENCIAS}

Arocha, Jaime (1999), Ombligados de Ananse: hilos ancestrales y modernos en el Pacífico colombiano, Bogotá: CES

Bhabha, Homi (1994), The location of culture, London: Routledge

Bourdieu, Pierre (2003), Firing back: against the tyranny of the market 2 (transl. Loic Wacquant), London: Verso

Buttimer, Anne (1976), "Grasping the dynamism of lifeworld", Annals of the Association of American Geographers 66(2), pp.277-292

Deleuze, Gilles \& Félix Guattari (2007) [1983], A thousand plateaus: capitalism and schizophrenia (trad. Brian Massumi), Minneapolis: University of Minnesota Press

Escobar, Arturo (1995), Encountering development: the making and unmaking of the Third World, Princeton: Princeton University Press

Escobar, Arturo (2008), Territories of difference: place, movements, life, redes, Durham: Duke University Press
Mundial como "utopía crítica”, Bourdieu (2003) reflexiona sobre el papel del intelectual colectivo como productor de "utopías realistas", o Escobar (2008: 196) afirma que "Las alternativas a la modernidad son la expresión de ... un deseo de la imaginación utópica crítica”. Por supuesto, Lefebvre (1976: 35) lo dijo bastante bien ya en la década de 1970: "hoy más que nunca, no hay ideas sin una utopía”.

Friedemann, Nina. S. de (1974), "Minería del oro y descendencia: Güelmambí, Nariño”, Revista Colombiana de Antropología 16, pp.9-52

García Márquez, Gabriel (2006) [1967], One hundred years of solitude, New York: Harper Collins

Granda, Germán de (1977), Estudios sobre un área dialectal hispanoamericana de población negra, Bogotá: Instituto Caro y Cuervo

Lefebvre, Henri (1976), "Reflections on the politics of space" (translated by $\mathrm{M}$. Enders), Antipode 8(2), pp.30-37

Mignolo, Walter (2011), The darker side of Western modernity: global futures, decolonial options, Durham: Duke University Press

Mignolo, Walter \& Arturo Escobar (eds) (2010), Globalization and the decolonial option, New York: Routledge

Oslender, Ulrich (2002), “The logic of the river: a spatial approach to ethnic-territorial mobilization in the Colombian Pacific region", Journal of Latin American Anthropology 7(2), pp.86-117 
Oslender, Ulrich (2004), "Fleshing out the geographies of social movements: black communities on the Colombian Pacific coast and the aquatic space", Political Geography 23(8), pp.957-985

Oslender, Ulrich (2016), The geographies of social movements: Afro-Colombian mobilization and the aquatic space, Durham: Duke University Press

Oslender, Ulrich (2018), “Local aquatic epistemologies among black communities on Colombia's Pacific Coast and the pluriverse", en B. Reiter (ed), Constructing the pluriverse: the geopolitics of knowledge, Durham, NC: Duke University Press, pp.137-150

PCN (Proceso de Comunidades Negras) (1999), El concepto de territorio en las comunidades negras del Pacífico Centro y Sur, organization's document

Quijano, Aníbal (2000), “Coloniality of power, Eurocentrism, and Latin America", Nepantla: Views from South 1(3), pp.533-580

Quijano, Aníbal (2007), “Coloniality and Modernity/Rationality", Cultural Studies 21(2-3), pp.168-178

Restrepo, Eduardo (1996a), "Los tuqueros negros del Pacífico Sur colombiano”, en J.I. Del Valle \& E. Restrepo (eds), Renacientes del guandal: 'grupos negros' de los ríos Satinga y Sanquianga, Bogotá: BiopacíficoUniversidad Nacional de Colombia, pp. $243-348$

Restrepo, Eduardo (1996b), “El naidí entre los 'grupos negros' del Pacífico Sur colombiano", en J.I. Del Valle \& E.
Restrepo (eds), Renacientes del guandal: 'grupos negros' de los ríos Satinga y Sanquianga, Bogotá: BiopacíficoUniversidad Nacional de Colombia, pp.351-383

Restrepo, Eduardo (2013), Etnización de la negridad: la invención de las 'comunidades negras' como grupo étnico en Colombia, Popayán: Universidad del Cauca

Said, Edward (1978), Orientalism, London: Routledge \& Kegan Paul

Santos, Boaventura de Sousa (2006), The rise of the global left: the World Social Forum and beyond, London: Zed Books

Santos, Boaventura de Sousa (2014), Epistemologies of the South: justice against epistemicide, New York: Routledge

Slater, David (2004), Geopolitics and the postcolonial: rethinking north-south relations, Oxford: Blackwell

Soja, Ed (1996), Thirdspace, Oxford: Blackwell

West, Robert (1952), Colonial placer mining in Colombia, Baton Rouge: Louisiana State University Press

West, Robert (1957), The Pacific lowlands of Colombia, Baton Rouge: Lousiana State University Press

Whitten, Norman (1986) [1974], Black frontiersmen: Afro-Hispanic culture of Ecuador and Colombia, Prospect Heights, Illinois: Waveland Press

Yacup, Sofonías (1934), Litoral recóndito, Bogotá: Editorial Renacimiento 


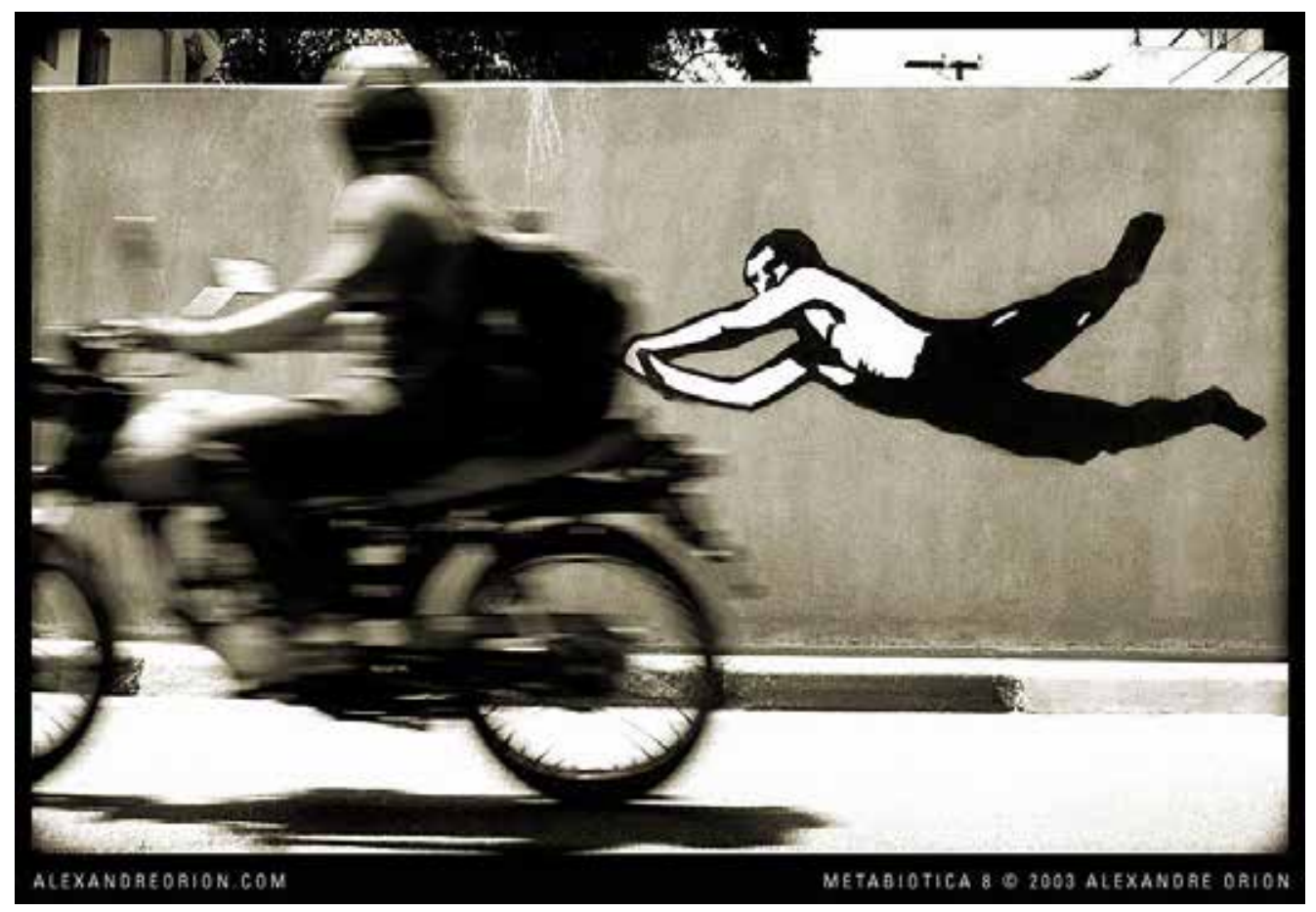

Metabiótica 8. 2003. Intervenção urbana seguida de registro fotográfico 